\title{
Socially mediated learning in male Betta splendens: II. Some failures
}

\author{
PAUL M. BRONSTEIN \\ University of Michigan-Flint, Flint, Michigan
}

\begin{abstract}
Male Siamese fighting fish were exposed to their mirror images inside distinctively colored tunnels and then were exposed to the tunnels without any mirrors. In contrast to earlier results, tunnel preferences were not established by these procedures. Observations of the animals during learning strongly suggest that seemingly minor changes in apparatus shape, relative to those of earlier experiments, produced the current failures of acquisition.
\end{abstract}

Experiments with Siamese fighting fish (Betta splendens) that had previously been interpreted as indicators of socially reinforced learning have more recently been criticized as ambiguous, that is, as creating confusions between learned behavior and unlearned species-specific acts (Bronstein, 1981, 1985, in press a). However, I have recently shown it possible to train male bettas to swim to particular locales if those sites have previously been baited with social cues (mirrors; Bronstein, in press b). Several different visual and/or spatial discriminations were taught to fish, indicating some role for socially mediated learning (and, perhaps, social reinforcement) in modulating bettas' swimming patterns. However, in attempts to extend this recent work on learning, failures of acquisition have been noted. The current paper documents those difficulties and suggests an explanation for this array of positive and negative findings.

\section{METHOD}

\section{Experiment 1A}

Subjects. Adult male Betta splendens, purchased from a local supplier, were used for all studies. Fish in both experiments were experimentally naive and had been housed in individual jars $(945 \mathrm{ml})$, visually isolated by opaque paper barriers, for at least 20 days prior to the start of any study. Feedings occurred in the mornings (flake food) and in the afternoons (thawed brine shrimp, Artemia spp.) 5 days a week (Monday through Friday). Subjects were exposed to $14 \mathrm{~h}$ of fluorescent light daily $(0800-2200 \mathrm{~h})$, with air and water temperatures maintained at $28^{\circ} \pm 2^{\circ} \mathrm{C}$. Tap water, aged at least 1 day and in which no fish had previously swum, was used throughout. Subjects' reactions to a conspecific image were assessed in the week prior to training: A mirror was placed outside and against each animal's jar for at most $5 \mathrm{~min}$, and only those fish erecting their gill covers in aggressive display were included in the subsequent study. This pretest mirror was removed shortly after a sub-

This paper was supported by grants from the Faculty Development Committee of the University of Michigan-Flint, Rackham Grants and a Rackham Fellowship from the University of Michigan-Ann Arbor, and by the National Institute of Mental Health (Grants MH 38792-01 and MH 33389-01). I am grateful to Larry Atherton, Jr., and William Mykolajenko for their excellent technical aid and to Sharon Mittan for her secretarial assistance.

Requests for reprints should be sent to Paul M. Bronstein, Department of Psychology, University of Michigan-Flint, Flint, MI 48502-2186. ject exhibited display. In attempting to determine whether social cues or reactions to them can mediate learning, fish that were unreactive to those social cues were not included in the current studies (cf. Bols, 1977; Hogan \& Bols, 1980).

Apparatus. The rectangular glass tanks used for training and testing were $20 \mathrm{~cm}$ wide, $41 \mathrm{~cm}$ long, and $27 \mathrm{~cm}$ high and were filled with $3 \mathrm{~cm}$ of undyed gravel beneath $10 \mathrm{~cm}$ of water. Each aquarium was placed with the back end ( $41 \mathrm{~cm}$ wide) facing a bare wall and the front $41-\mathrm{cm}$ end extending toward the central part of the laboratory. Opaque brown paper covered the tanks' two short sides and hollow J-shaped tunnels were periodically placed in the two adjacent corners at the tanks' back ends. These tunnels were constructed from sheets of white perforated styrene glued with silicon cement. Each tunnel had a back $(12.5 \mathrm{~cm}$ wide) and two sides (15 and $7.5 \mathrm{~cm}$ long), with its top, bottom, and one side open. The inside of each tunnel was covered with either red or green plastic tape (3M Scotch Brand, Nos. 191 and 193), and all surfaces of each tunnel were then covered with a thin layer of clear silicon. Once in place, with the $15-\mathrm{cm}$ side of each tunnel abutting and parallel to one of a tank's $20-\mathrm{cm}$ walls and with their open sides facing the front ends of the tanks, the tunnels $(12.5 \mathrm{~cm}$ high) extended about $1 \mathrm{~cm}$ above waterline. The upper panel of Figure 1 is a top view of a tank following the addition of two tunnels.

Procedure. Both experiments included two groups of male Betta splendens. On the morning of the first training day, fish were rehoused from their jars to their individual tanks, where they remained throughout the studies. For Experiment 1A, each animal was administered one training session daily for 4 consecutive days. Training sessions lasted $30 \mathrm{~min}$ and were initiated by the insertion of the two tunnels-one red, one green-into adjacent rear corners of each tank (see Figure 1).

During the four training periods, a mirror was placed inside either the red or green tunnel, with 10 fish getting each visual cue paired with the social US. Also, the positions of the tunnels were varied semirandomly during training. For odd-numbered sessions, tunnel positions were determined randomly for each animal, with the spatial arrangements of tunnels on even-numbered sessions being the opposite of those used during the preceding training period.

As depicted in the upper panel of Figure 1, mirrors were presented at the rear of the tunnels during training. Mirror presentations were accomplished by cutting a centrally located square window $(9 \times 9 \mathrm{~cm})$ in the back of each tunnel; either a mirror or a piece of plastic (covered with silicon and identical in color to the tunnel) was placed behind the opening. Fish were observed intermittently during training, and training sessions concluded with the removal of tunnels and mirrors.

Test sessions ( $30 \mathrm{~min}$ in duration and occurring $24 \mathrm{~h}$ after the final training period) were indistinguishable from the training sessions, except that no mirror was available in either tunnel. The square windows where mirrors might be shown were each covered with a piece of siliconcoated plastic; these inserts were of the same color as the tunnels in which they were located. Also, the positions of the tunnels were determined randomly. Subjects were observed throughout tests to determine whether the prior experience of a mirror in conjunction with either the 
red or green tunnel would cause fish to be attracted to that particular cue. The number of seconds subjects spent inside or in front of each tunnel (between the tunnels and the front of the tanks) was recorded. It was also expected that fish would issue gill-cover displays while inside the tunnel previously paired with the conspecific image (cf. Bronstein, in press b; Thompson \& Sturm, 1965).

\section{Experiment 1B}

Using the same apparatus and similar procedures used in the first study, two additional groups were trained-one group presented with mirrors in the red tunnels, the other group with mirrors inside the green tunnels. However, in this replication, fish were given two 40-min training trials per day for 4 consecutive days. Testing occurred approximately $20 \mathrm{~h}$ after the last training period.

\section{RESULTS AND DISCUSSION}

As noted in Table 1, there was no evidence for the learning of a red-green discrimination in either study. In spite of the association of mirrors with either red or green CSs, there were no reliable between-groups differences in preference for the tunnels in either study. Furthermore, only 1 fish in each study (i.e., 2 of 44 subjects) exhibited gill-cover display during testing. These learning failures occurred in spite of the facts that (1) easily discriminable tunnel colors were used, and (2) CSs and USs were paired for time periods previously shown to be adequate for establishing learning (Bronstein, in press b).

The current failures of acquisition were probably due to the interactions of bettas' species-specific agonistic repertoire with the geometry of the apparatus. Most males confronting a proximate conspecific image initially display near that stimulus and then quickly escape, return-

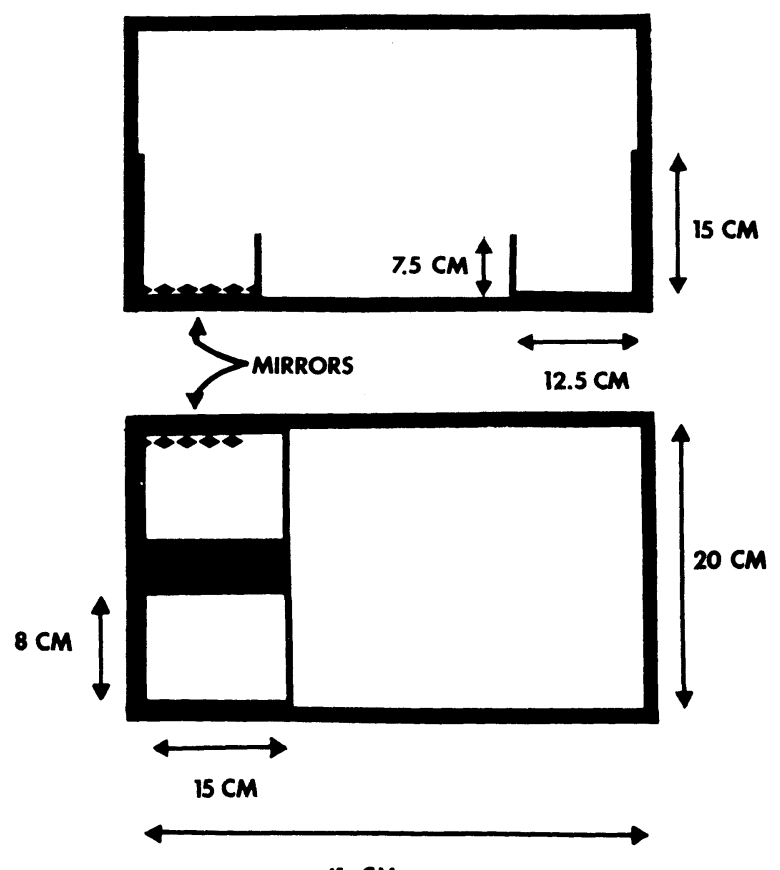

$41 \mathrm{CM}$

Figure 1. Top views of the training apparatus used in the current studies (upper panel) and in prior experiments (Bronstein, in press b; lower panel).
Table 1

Tunnel Preferences in Both Studies

\begin{tabular}{|c|c|c|c|c|}
\hline Groups & $\begin{array}{l}\text { Mean Seconds } \\
\text { at Red (SEM) }\end{array}$ & $t$ & $\begin{array}{l}\text { Mean Seconds } \\
\text { at Green (SEM) }\end{array}$ & $t$ \\
\hline \multicolumn{5}{|c|}{ Experiment $1 \mathrm{~A}$} \\
\hline $\operatorname{Red}(n=10)$ & 539 (44.9) & & $709(52.2)$ & \\
\hline Green $(n=10)$ & $527(66.9)$ & 0.15 & $851(69.4)$ & 1.64 \\
\hline \multicolumn{5}{|c|}{ Experiment 1B } \\
\hline Green $(n=12)$ & $566(57.7)$ & & $620(49.1)$ & \\
\hline Green $(n=12)$ & $485(55.1)$ & 1.01 & $720(69.3)$ & 1.18 \\
\hline
\end{tabular}

ing to their nests if one exists. For most fish, this conflict behavior then persists for some 10s of minutes (Bronstein, 1985). When coupled with the apparatus shown in the lower portion of Figure 1 (used by Bronstein, in press b), this ethogram resulted in learning. Fish in those experiments entered the tunnels that were baited with mirrors and either persisted there in attack behaviors, or quickly escaped to the opposite nontunnel sides of their tanks only to be deflected back into the tunnels by the glass walls of their tanks. Thus, apparatus geometry, coupled with the trajectory of animals' agonistic swimming patterns, set up numerous tunnel entries, and hence, many experiences of fish displaying to a mirror image while inside one distinctively colored tunnel, along with some nonaggressive experiences while inside the other tunnel.

However, the intermittent observations of fish during the training phase of the current experiments revealed an entirely different pattern of swimming and agonistic display. In the apparatus depicted in the upper panel of Figure 1, subjects, when escaping their mirror images, had a relatively large area in which to swim between the two tunnels. It was common during training to find bettas spending much of the time during their sessions swimming slowly between the two tunnels and encountering neither the mirror nor either of the colored tunnels. In short, the apparatus geometry of the current studies appeared to produce many fewer tunnel and mirror experiences than did that used in the earlier work (Bronstein, in press b). The two apparatuses shown in Figure 1 are superficially identical; however, their slightly different geometries resulted in drastically different behaviors, with the current apparatus seeming to provide the more limited, and, as it turned out, inadequate learning opportunities.

\section{REFERENCES}

BoLs, R. J. (1977). Display motivation in the Siamese fighting fish Betta splendens: Aggressive motivation or curiosity? Journal of Comparative \& Physiological Psychology, 91, 233-244.

Bronstein, P. M. (1981). Social reinforcement in Betta splendens: A reconsideration. Journal of Comparative \& Physiological Psychology, 95, 943-950.

Bronstein, P. M. (1985). Toxiphobia, "social reinforcement," comparative psychology, and Patrick J. Capretta. In N. S. Braveman \& P. M. Bronstein (Eds.), Experimental assessments and clinical applications of conditioned food aversions (pp. 158-167). New York: New York Academy of Sciences. 
BronsteIN, P. M. (in press a). Reductionist and comparative approaches to social behavior in Siamese fighting fish. In G. Greenberg \& E. Tobach (Eds.), The T. C. Schneirla conference series: Vol. 3. Evolution of social behavior and integrative levels. Hillsdale, $\mathrm{NJ}$ : Erlbaum.

BRonsteIn, P. M. (in press b). Socially mediated learning in male Betta splendens. Journal of Comparative Psychology.

HogaN, J. A., \& Bols, R. J. (1980). Priming of aggressive motivation in Betta splendens. Animal Behaviour, 28, 135-142.
Thompson, T., \& STURM, T. (1965). Classical conditioning of aggressive display in Siamese fighting fish. Journal of the Experimental Analysis of Behavior, 8, 397-403.

(Manuscript received for publication March 31, 1986.) 